\title{
Selecting behaviour change techniques to reduce sedentary behaviour in people with stroke using the Behaviour Change Wheel
}

\author{
Roderick Wondergem ( $\nabla$ r.wondergem@fontys.nl ) \\ Universitair Medisch Centrum Utrecht https://orcid.org/0000-0003-2611-7963 \\ Wendy Hendrickx \\ Universitair Medisch Centrum Utrecht
}

\section{Eveline Wouters}

Tilburg University Tranzo Scientific Centre for Care and Welfare

Rob de Bie

Universiteit Maastricht

Johanna Visser

Universitair Medisch Centrum Utrecht

Cindy Veenhof

Universitair Medisch Centrum Utrecht

Martijn Pisters

Universitair Medisch Centrum Utrecht

\section{Research article}

Keywords: sedentary behaviour, stroke, behaviour change, intervention development, movement behaviour, secondary prevention

Posted Date: July 24th, 2020

DOI: https://doi.org/10.21203/rs.2.10822/v2

License: @ (i) This work is licensed under a Creative Commons Attribution 4.0 International License. Read Full License 


\section{Abstract}

Background: Research has shown that sedentary behaviour increases the risk of stroke, cardiovascular disease and mortality. People with stroke are highly sedentary. Therefore, reducing sedentary behaviour might reduce the risk of secondary events and death. Personalized strategies using behavioural change techniques (BCTs) directed at reducing sedentary behaviour in people with stroke are currently lacking. Therefore, the aim of this study is to systematically determine the BCTs for a behavioural change intervention, directed at reducing sedentary behaviour in community-dwelling people with stroke,.

Method: To complete the stages of the Behaviour Change Wheel, information on understanding the behaviour, identifying intervention functions, identifying BCTs and modes of delivery were needed. Per stage a literature search was conducted and nominal group technique (NGT) sessions were conducted to identify BCTs. The NGT sessions were conducted with professionals working with people with stroke and international researchers working in the stroke or sedentary behaviour field. Four different patients symptom profiles, as frequently seen in clinical practice, were used by participants during the NGT sessions: : 1. no physical or cognitive impairments; profile 2 . mainly cognitive impairments; profile 3 . mainly physical impairments; and profile 4. both physical and cognitive impairments. Per profile participants made their choice by rating the BCTs.

Results: Five BCTs should always be included: 'goal setting', 'action planning', 'social support', 'problem solving' and 'restructuring of the social environment'. For patients without cognitive impairments, 'selfmonitoring', 'feedback on behaviour', 'information about health consequences' and 'goal setting on outcome' were advised to be included, while for patients with cognitive impairments, 'prompts/cues', 'graded tasks', 'restructuring the physical environment' and 'social support practical' should be considered.

Conclusion: BCTs were identified for a behavioural change intervention aiming to reduce sedentary behaviour in community-dwelling people with first-ever stroke. BCTs recommendations depend on the presence of physical and cognitive impairments, although 'goal setting', 'action planning', 'social support', 'problem solving' and 'restructuring of the social environment' are recommended in all people with first-ever stroke. The identified BCTs serve as the basis for further development of a personalized blended care intervention to reduce sedentary behaviour in people with stroke.

\section{Contributions To Literature}

A behavioural diagnosis including barriers, facilitators and opportunities to replace sedentary behaviour with physical activity in people with stroke is provided.

- Different BCTs were selected in people with stroke with cognitive complains compared to people with predominantly physical complaints, which emphasizes a personalized approach.

- Regardless of the complaints after stroke 'goal setting', 'action planning', 'social support', 'problem solving' and 'restructuring of the social environment' should always be included in interventions aiming 
to replace and interrupt sedentary behaviour with physical activity.

\section{Background}

Over twenty-five percent of people with stroke experience a recurrent event within five years (1). Key risk factors for recurrent stroke are cardiovascular risk factors such as hypertension and impaired glucose tolerance $(2,3)$. Reduction of the recurrence of stroke is in the top ten priorities for people with stroke (4). Therefore, secondary prevention after a first-ever stroke is important. Sedentary behaviour increases the risk of all-cause mortality and cardiovascular disease including stroke (5-9). Studies show that a reduction in the total amount of sedentary time reduces metabolic risk factors, like hypertension and impaired glucose tolerance, associated with an increased risk of cardiovascular diseases $(7,10,11)$. Additionally, prolonged uninterrupted sedentary time, independent of total sedentary time, is associated with poor health and elevated cardiovascular risk factors $(7,11-15)$. In people with stroke a clinical relevant decrease of blood pressure was found by reducing and interrupting sedentary behaviour (16). Decreasing sedentary behaviour could already produce health benefits in people with stroke $(6,10,14,17)$.

Research has shown that people with stroke are even more sedentary compared to healthy peers and sedentary time is accumulated in longer uninterrupted sedentary bouts (18-21). Since up to $40 \%$ of people with stroke experience a decline in activities of daily living after rehabilitation, it is important for patients to have self-management skills to preserve physical functioning (22). In an elderly population, even small reductions in sedentary behaviour increase physical functioning and decrease the prevalence of cardiovascular risk factors and mortality (23-25). Additional to possible health benefits, decrease of sedentary behaviour could contribute to prevention of decline in physical functioning in people with stroke.

Only two intervention studies evaluated the effect of influencing sedentary time in a stroke population. The results of these studies are promising $(26,27)$. The first study focused on increasing physical activity instead of reducing sedentary behaviour, in addition, sedentary behaviour was a secondary outcome measure (26). When targeting the reduction of sedentary behaviour, the focus of an intervention should be primarily on reducing sedentary time and interrupting sedentary bouts $(6,23)$. The second study was a feasibility study focussing on decreasing sedentary time and with a small sample (27). At this moment, a systematically developed intervention to reduce sedentary behaviour in stroke survivors is lacking.

Before developing a behaviour change intervention, well-defined intervention techniques for people with stroke need to be identified. The Behaviour Change Wheel (BCW), is a step-by-step theory-based approach to develop behaviour change interventions. The BCW is based on all behaviour change frameworks and theories that currently exist $(28,29)$ (see figure I). The wheel has four layers. The first layer, the green part of the wheel, starts with Capability (physical and psychological), Opportunity (social and physical) and Motivation (automatic and reflective) influencing behaviour model (COM-B). These three factors enhance the likelihood of performing a specific behaviour. The second layer, the yellow part, is the Theoretical Domains Framework which supports the behaviour model. The Theoretical Domains Framework consists 14 factors that are connected to a COM-B category (figure I). These 14 factors are: physical skills; knowledge; cognitive 
and interpersonal skills; memory, attention and decision processes; behavioural regulation; environmental context and resources; social influences; professional/social role and identity; beliefs about capabilities; optimism; beliefs about consequences; intentions; goals; reinforcement; emotion. The third layer, the red part, contains nine intervention functions (Education, Persuasion, Incentivisation, Coercion, Training, Enablement, Modelling, Environmental Restructuring and Restrictions). Intervention functions are broad categories of means by which an intervention can change behaviour. The intervention functions are linked to BCTs. The BCTs are the observable, replicable, irreducible and active components of an intervention to change behaviour (29). The fourth and final layer, the grey part, are the policy categories. These categories can be used to support the delivery of the intervention functions.

An intervention to reduce sedentary behaviour in people with stroke should be personalized to improve outcome (30). Additionally, personalization improves adherence and the uptake to the prescribed therapy (30). Therefore, this study aims to systematically determine the behaviour change techniques (BCTs) for a behavioural change intervention, directed at reducing sedentary behaviour in community-dwelling, using the stages of the BCW.

\section{Method}

The step by step approach of the BCW was used to selected appropriate BCTs. The BCW involved a series of stages. These three stages are: 1 . Understanding the behaviour; 2 . Identify intervention functions; and 3. Identify BCTs and modes of delivery. Per stage different methods were used to collected the information. Literature was searched until September 2018 within PubMed and Cinahl. Search strategies were formulated for Pubmed and adapted for use in Cinahl. Both the stages and the used methods are presented in figure II. Each stage is described in more detail below.

\section{Stage 1: Understanding the behaviour}

In stage 1, first the target behaviour was defined, selected and specified using existing literature and by discussion in the research team. The research team consisted of six experts in the field of stroke, rehabilitation, physiotherapy, movement behaviour and/or behavioural change. Second, a literature search was conducted to get insight into the behavioural diagnosis. The researchers $\mathrm{WH}$ and $\mathrm{RW}$ conducted a literature study to identify motivators, barriers and opportunities regarding sedentary behaviour in people with stroke (see table I for search terms). Literature was searched until no new motivators, barriers and opportunities were found. The motivators, barriers and opportunities were connected to the COM-B model and the Theoretical Domains Framework (figure I) by WH and RW. The results were discussed in the research team and adjustments were made where needed.

\section{Stage 2: Identify intervention functions,}

To identify effective intervention functions a literature search was conducted. Effective intervention functions were retrieved out of literature by WH and RW. Search terms used are presented in table I. The 


\section{Stage 3: Identify behaviour change techniques and modes of delivery}

First, effective BCTs and the modes of delivery were identified from the literature. Second, Nominal Group Technique (NGT) sessions with professionals working with people with stroke and researchers were undertaken.

\section{Literature research}

Effective BCTs and modes of delivery were retrieved from the literature by WH and RW. Search terms used are presented in table I. An overview of BCTs that were found to be effective, not effective, conflicting evidence or no evidence to reduce sedentary behaviour was made. WH and RW independently recoded the BCTs of the retrieved intervention studies to the BCW method if needed. In case of disagreement, a third researcher (MP) was consulted. Effective modes of delivery were listed.

\section{Nominal Groups Techniques}

After the literature study, Nominal Groups Technique sessions were performed and facilitated by WH and RW. The Nominal Group Technique sessions were undertaken because it was expected that the retrieved BCTs were mainly based on a healthy population. Instead, interventions should be tailored to people with stroke and therefore other BCTs could be more suitable to the stroke population. Additional, symptoms after stroke are diverse and personalization of interventions is needed to improve the uptake of an intervention $(30,31)$. Therefore, four profiles of people with stroke were formulated by the research team based on literature (31) and best practice experience: profile 1. no physical or cognitive impairments; profile 2. mainly cognitive impairments; profile 3. mainly physical impairments; and profile 4. both physical and cognitive impairments.

Two groups were empanelled formulated to carry out the Nominal Group Technique sessions. Group one, professionals, consisted of physiotherapists working with people with stroke in a hospital, rehabilitation centre and in private practice. All professionals were working in the stroke service of Utrecht. Group two, researchers, were working in the field of behavioural change, people with stroke and movement behaviour. International researchers were asked by email to participate in this study. Since the researchers reside in different parts of the world, it was decided to use individual interviews within the NGT structure to receive their input on the content of the intervention. Both the groups session and interviews were audio recorded.

Both professionals and experts received an overview of the BCTs found in literature to be effective, not effective, generating conflicting evidence or no evidence before the interview or NGT face-to-face session. 
The professionals and researchers were asked to identify all BCTs that might be relevant for the intervention. Based on the answers, the possible relevant BCTs were provided to all participants. The participants and researchers were asked to individually choose the eight most important BCTs per profile to reduce sedentary behaviour in people with stroke (32). Each individual made their choice by rating the BCTs; eight points were given to the BCT deemed most important, seven points to the second most important BCT and so on. The scores of the individuals were summed per stroke profile, resulting in an overview of the most important BCTs to reduce sedentary behaviour per profile.

\section{Results}

\section{Stage 1: Understanding the behaviour}

Based on existing literature and discussion within the research group two target behaviour were selected. The first target behaviour is to reduce total time spent sedentary $(5-12,14,33)$. The BUST-study found a statistically and clinically relevant decrease of the systolic blood pressure by interrupting sedentary behaviour every thirty minutes with a walk of three minutes (16). Therefore, the second target behaviour is to reduce time spent in sedentary behaviour accumulated in bouts over thirty minutes.

From the literature study searching motivations, barriers and opportunities to reduce sedentary behaviour in people with stroke, one study including people after stroke was found (34). The study found that there is limited awareness of health risks of sedentary behaviour among people with stroke. The main reasons for sedentary behaviour were relaxation, comfort, sedentary occupation or inability to get back to work. It was concluded that participants encountered barriers in their daily lives that affect engagement in activity. The main barriers are motor impairments, fatigue, cognitive problems, depression, lack of support from friends and family and lack of motivation to be physically active.Strategies involving wearable technologies for selfmonitoring, movement throughout the day and action planning to reduce sedentary behaviour were found as potential ways to reduce sedentary behaviour according to people with stroke. An additional search focussing an elderly population resulted in one study including elderly women (35). This resulted in fifteen reasons to sit, fourteen motivators and six opportunities. All motivators, barriers and opportunities were connected to the COM-B model and Theoretical Domains Framework and can be found in table II.

\section{Stage 2 Identify intervention functions}

No evidence was found on intervention functions specific to reduce sedentary behaviour in people with stroke. Three systematic reviews were found on reducing sedentary behaviour in general populations (3638). The following intervention functions were found to be effective and connected to the TDF domains (see table II): persuasion, incentivisation (based on one study), training, environmental restructuring and restriction. 


\section{Stage 3: Identify behaviour change techniques and modes of delivery}

\section{Literature study}

No evidence on BCTs and modes of delivery specific to reduce sedentary behaviour was found for people with stroke. Three systematic reviews were found on reducing sedentary behaviour in general populations $(36-38)$. The overall conclusion of the reviews was that lifestyle interventions targeting sedentary behaviour specifically or targeting sedentary behaviour and physical activity at the same time are effective (36-38) for reducing sedentary time. One review already recoded the content of the included interventions to BCT (37). For the other two reviews, the authors RW and WH recoded the content of the included interventions to BCTs $(36,38)$. An overview of BCTs that were found to be effective is provided in additional file I, table I. The identified modes of delivery were face to face group, web-based personal, written materials and activity monitors.

\section{Nominal Group Techniques sessions}

In total, six professionals and five researchers participated in the Nominal Group Techniques sessions. The average age of the professionals was 36 years (range 23 to 51). The average work experience was 13 years (range 2 to 30). All had a bachelor's degree in physiotherapy, and two had an additional master's degree in physiotherapy sciences. Two currently worked in an academic hospital, two worked in a rehabilitation centre and two worked in private practice. All of the professionals were working with people with stroke on a regular basis. The average age of the researchers was 44 (range 41 to 49 ). All but one had a background as a physiotherapist; the other one was a neuropsychologist. All researchers had a PhD and worked at least parttime as a researcher. All had movement behaviour and/or stroke as their area of expertise.

The participants identified, in total, $75 \mathrm{BCTs}$ as possibly eligible to include in an intervention to reduce sedentary behaviour. A mean of 30 BCTs per profile received points (range 29-33 BCTs). Overall 'goal-setting', 'action planning', 'social support', 'problem solving' and 'restructuring the social environment' were selected in all four profiles. 'Self-monitoring', 'feedback on behaviour', 'information about health consequences' and 'goal setting on outcome' were selected for both profiles without cognitive impairments, and 'prompts/cues', 'graded tasks', 'restructuring the physical environment' and 'social support practical' were selected for both profiles with cognitive impairments. An overview of the ten most eligible BCTs per profile can be found in table III. An overview of the ranking and frequency of the BCTs for the four different profiles can be found in Additional file I, table II - V .

\section{Discussion}

The aim of this study was to determine BCTs for a behavioural change intervention to reduce sedentary behaviour in people with stroke using the BCW. BCTs were ranked by professionals and researchers after the 
literature was reviewed and the main elements were extracted. In summary, 'goal-setting', 'action planning', 'social support', 'problem solving' and 'restructuring the social environment' were found to be main elements to be included in an intervention to reduce sedentary behaviour in all people with stroke.

\section{Target behaviour}

Reducing sedentary behaviour needs to be the target behaviour and the focus within an intervention, rather than enhancing physical activity (37). Sedentary behaviour and reaching sufficient levels of physical activity are two different behavioural constructs (39). Additionally, it is difficult for people with stroke to achieve adequate levels of moderate to vigorous physical activity (40). Focussing entirely on sedentary behaviour can already contribute to secondary prevention and could be more achievable for people with stroke, including those with ambulatory difficulties. However, a part of the population could be able to reach sufficient amounts of physical activity. In this subpopulation, sedentary interventions should be implemented alongside physical activity and exercise interventions to reach an optimal reduction of cardiovascular risk factors (39).

It remains unclear how much reduction is needed in total sedentary time and in breaking up prolonged bouts of sedentary behaviour to gain health benefits. Already, small improvements seem to have health benefits in other populations $(9,13,14)$.

\section{Motivators, Barriers and Opportunities}

Only one study is conducted investigating the barriers and motivators to reduce sedentary behaviour in people with stroke. This study provided important information with regards to the capabilities, opportunities and motivators in people with stroke to remain sedentary (34). However, for further development of the intervention content it will be important to include people with stroke and their carers to be sure the content connects to the target population $(41,42)$.

\section{Behaviour Change Techniques}

The identification of BCTs was accomplished through the comprehensive use of the BCW. The BCW ensures that there is a clear definition of the behaviour and the change needed; this is to make sure there is a thorough understanding of all the aspects of the behaviour.

At least seven BCTs should be included in an intervention. In a review on reducing sedentary behaviour in a general population, it was found that effective interventions included at least seven BCTs (37). Little is known about the amount of BCTs therefore, we presented the top ten BCTs per profile. However, more research is needed to include the sufficient amount of BCTs in an intervention.

Personalization of care is important especially in the stroke population were complaints after stroke are divers (30). Although self-monitoring seems to be one of the most important BCTs to reduce sedentary 
behaviour, this could be difficult to implement, interpret and translate into behaviour change in people with stroke with cognitive problems (43). A different approach for these patients could be more effective. The results of our study show that social support needs to be included in the intervention for people with stroke with cognitive impairments. The involvement and support of family and friends is therefore highly recommended. Additionally, $68 \%$ of people with stroke have at least one cognitive complaint (44), and the variety of physical limitations is wide (45). This underlines the importance of tailoring the intervention (30). When the individual needs, limitations and motivators of people with stroke are taken into account adherence to the intervention will increase (30). The profiles used in our study can guide the selection of BCTs and the personalization of the intervention.

In this study, the most important BCTs to reduce sedentary behaviour in people with stroke were identified. Further research should focus on the effectiveness of the BCTs for both target behaviours, i.e., sedentary behaviour, in people with stroke. In such research, it is essential to describe BCTs using the Behaviour Change Technique Taxonomy (29). Thorough intervention descriptions in protocol articles are needed and intervention protocols should be available to use in practice. Description of included BCTs, the frequency of use, the intensity and the way BCTs are delivered are important as is education to implement and execute BCTs in daily practice. For example goal-setting is one of the most important BCTs recommended in stroke rehabilitation (46). However, the determination of goal-setting seems to be difficult, and health care professionals find it difficult to make goals that are patient-centred (47-49). Education to overcome these problems could be explored and implemented to improve the quality of goal-setting.

\section{Modes of delivery}

The identified modes of delivery were face to face contact, group delivery, web-based personal, written materials standard and activity monitors. The results of our study underline the importance of a blended care intervention. To optimize personalized secondary prevention, blending care seems to be promising. The use of computer, mobile and wearable device (eCoaching) can be effective to reduce sedentary behaviour (50). Persuasive eCoaching, the use of technology during coaching to motivate and stimulate people to change attitudes, behaviour and rituals (41), could be a useful in reducing sedentary behaviour in people with stroke but this needs further research. ECoaching on its own showed only short term effects (50). Whereas, eCoaching and face-to-face contacts together showed more sustainable behavioural changes (51). However, this is not yet investigated in people with stroke. Activity monitors are highly important to gain insight into the individual behaviour and give real time feedback on behaviour (37). Therefore, an intervention including activity trackers, persuasive eCoaching and face-to-face contact could be a promising approach (41). Although the most important modes of delivery and BCTs are identified, a detailed description of an intervention needs to be further explored.

\section{Study limitations}

Based on the amount of consistent literature found and the thoroughness of the search, the literature research seems complete and comprehensive, although this is not a systematic review. Some information 
was retrieved out of other populations and should be further investigated in a population with people with stroke. Another limitation is that even though the description of the BCTs is quite elaborate, there is still some room for interpretation. Care was taken to make comprehension of the BCTs as clear as possible.

To get the insights of the researchers, the original Nominal Group Techniques process could not be followed. To make sure the most renowned researchers were involved in the selection of the BCTs, it was decided to include not just Dutch experts but researchers from around the world. Therefore, the NGT method was converted into an interview-based method. Although some of the group dynamics were compromised, a step-based method was used to ensure that all participants were informed of the identified possible BCTs before the individual ranking.

Almost all participants stated that their choice of the use of a BCT in clinical practice is partially based on the person in front of them and their limitations caused by the stroke. This is in line with the distinction made in the ranking by using the four profiles; these profiles are an attempt, at this point in the development, to do as much justice as possible to the individual differences. However, personal factors have to been taken into account. Additional to stroke characteristics personal factors like coping style, neuroticism and optimism are associated with functioning after stroke (52). When personalize an intervention these factors should be taken in to account. This study provides important information to personalize an intervention by selecting the right BCTS and mode of delivery based on the individual. Within the development of an intervention all stakeholders should be included. Within the design team for behavioural change interventions in stroke patients all professionals involved in stroke care, people with stroke themselves, proxies, behavioural experts and as well as technology experts should be included from the start of the design process (42).

\section{Conclusion}

Behaviour change techniques were identified for a behavioural change intervention aiming to reduce sedentary behaviour in community-dwelling people with first-ever stroke. BCTs recommendations depend on the presence of physical and cognitive impairments, although 'goal setting', 'action planning', 'social support', 'problem solving' and 'restructuring of the social environment' is recommended in all people with first-ever stroke. The identified BCTs serve as the basis for further development of a personalized blended care intervention to reduce sedentary behaviour in people with stroke.

\section{List Of Abbreviations:}

$\mathrm{BCW}=$ Behaviour Change Wheel

$\mathrm{BCTs}=$ behaviour change techniques

COM-B=capacity, opportunity and motivation influencing behaviour model

TDF=Theoretical Domains Framework

Page 10/26 
APEASE=Affordability, Practicability, Effectiveness and cost-effectiveness, Acceptability, Side-effects/safety and Equity

NGT=nominal group technique

\section{Declarations}

Ethics approval and consent to participate

Ethical approval was not applicable to this study since researchers and professionals were included.

Informed consent was given by all participants and the studies were performed in accordance with the Declaration of Helsinki. Professionals gave written informed consent and researchers gave oral consent. Oral consent was audio reordered.

Consent for publication

Not applicable

Availability of data and material

The NGT ratings are included as additional file.

Competing interests

The authors declare that they have no competing interests.

Funding

Dutch Organization for Scientific Research (NWO), Doctoral Grant for Teachers, 023.003.136. The grant was assigned to Roderick Wondergem. The grant facilitated Roderick Wondergem to carry out the study. Funding had no further involvement in the study process.

\section{Authors' contributions}

RW, MP, CV, AV, RB, and EW and designed the study. RW and WH collected the data. RW, WH and MP wrote the first draft of the manuscript with substantial input from CV, AV, RB, and EW. RW, MF, RA, CV and AV secured the research funding. All authors contributed to this manuscript, and all read and approved the final version.

\section{References}

1. Mohan KM, Wolfe CDA, Rudd AG, Heuschmann PU, Kolominsky-Rabas PL, Grieve AP. Risk and cumulative risk of stroke recurrence: A systematic review and meta-analysis. Stroke. 2011;42:1489-94. 
2. Fonville S, Zandbergen AAM, Koudstaal PJ, den Hertog HM. Prediabetes in Patients with Stroke or Transient Ischemic Attack: Prevalence, Risk and Clinical Management. Cerebrovasc Dis. 2014;37:393-400.

3. Sacco RL. Newer risk factors for stroke. Neurology. 2001;57:S31-4.

4. Pollock A, St George B, Fenton M, Firkins L. Top 10 research priorities relating to life after strokeconsensus from stroke survivors, caregivers, and health professionals. Int J Stroke. 2014;9:313-20.

5. van der Ploeg HP, Chey T, Korda RJ, Banks E, Bauman A. Sitting time and all-cause mortality risk in 222 497 Australian adults. Arch Intern Med. 2012;172:494-500.

6. Tremblay MS, Colley RC, Saunders TJ, Healy GN, Owen N. Physiological and health implications of a sedentary lifestyle. Appl Physiol Nutr Metab. 2010;35:725-40.

7. Owen N, Healy GN, Matthews CE, Dunstan DW. Too Much Sitting. Exerc Sport Sci Rev. 2010;38:105-13.

8. Biswas A, Oh PI, Faulkner GE, Bajaj RR, Silver MA, Mitchell MS, et al. Sedentary time and its association with risk for disease incidence, mortality, and hospitalization in adults: a systematic review and metaanalysis. Ann Intern Med. 2015;162:123-32.

9. Biddle SJH, Bennie JA, Bauman AE, Chau JY, Dunstan D, Owen N, et al. Too much sitting and all-cause mortality: is there a causal link? BMC Public Health. 2016;16:635.

10. Bauman AE, Chau JY, Ding D, Bennie J. Too Much Sitting and Cardio-Metabolic Risk: An Update of Epidemiological Evidence. Current Cardiovascular Risk Reports. 2013;7:293-8.

11. Healy GN, Dunstan DW, Salmon J, Cerin E, Shaw JE, Zimmet PZ, et al. Breaks in Sedentary Time: Beneficial associations with metabolic risk. Diabetes Care. 2008;31:661-6.

12. Dunstan DW, Howard B, Healy GN, Owen N. Too much sitting--a health hazard. Diabetes Res Clin Pract. 2012;97:368-76.

13. Benatti FB, Ried-Larsen M. The Effects of Breaking up Prolonged Sitting Time: A Review of Experimental Studies. Medicine and Science in Sports and Exercise Oct, 2015;2053-61.

14. Chastin SFM, Egerton T, Leask C, Stamatakis E. Meta-analysis of the relationship between breaks in sedentary behavior and cardiometabolic health. Obesity. 2015;23:1800-10.

15. Healy GN, Matthews CE, Dunstan DW, Winkler EAH, Owen N. Sedentary time and cardio-metabolic biomarkers in US adults: NHANES 200306. Eur Heart J. 2011;32:590-7.

16. English C, Janssen H, Crowfoot G, Bourne J, Callister R, Dunn A, et al. Frequent, short bouts of lightintensity exercises while standing decreases systolic blood pressure: Breaking Up Sitting Time after Stroke (BUST-Stroke) trial. Int J Stroke. 2018; 
17. Manns PJ, Dunstan DW, Owen N, Healy GN. Addressing the nonexercise part of the activity continuum: a more realistic and achievable approach to activity programming for adults with mobility disability? Phys Ther. 2012;92:614-25.

18. English C, Manns PJ, Tucak C, Bernhardt J. Physical activity and sedentary behaviors in people with stroke living in the community: a systematic review. Phys Ther. 2014;94:185-96.

19. Paul L, Brewster S, Wyke S, Gill JMR, Alexander G, Dybus A, et al. Physical activity profiles and sedentary behaviour in people following stroke: a cross-sectional study. Disabil Rehabil. 2016;38:362-7.

20. Tieges Z, Mead G, Allerhand M, Duncan F, van Wijck F, Fitzsimons C, et al. Sedentary behaviour in the first year after stroke: a longitudinal cohort study with objective measures. Arch Phys Med Rehabil. 2015;96:1523

21. Moore SA, Hallsworth K, Plötz T, Ford GA, Rochester L, Trenell MI. Physical activity, sedentary behaviour and metabolic control following stroke: a cross-sectional and longitudinal study. PLoS One. 2013;8:e55263.

22. Wondergem R, Pisters MF, Wouters EJ, Olthof N, De Bie RA, Visser-Meily JMA, et al. The course of activities in daily living: Who is at risk for decline after first ever stroke? Cerebrovasc Dis. 2017;43.

23. Wullems JA, Verschueren SMP, Degens $\mathrm{H}$, Morse $\mathrm{Cl}$, Onambélé $\mathrm{GL}$. A review of the assessment and prevalence of sedentarism in older adults, its physiology/health impact and non-exercise mobility countermeasures. Biogerontology. 2016;17:547-65.

24. Gerage AM, Benedetti TRB, Farah BQ, Santana F da S, Ohara D, Andersen LB, et al. Sedentary Behavior and Light Physical Activity Are Associated with Brachial and Central Blood Pressure in Hypertensive Patients. Tordjman KM, editor. PLoS One. 2015;10:e0146078.

25. Matthews CE, Moore SC, Sampson J, Blair A, Xiao Q, Keadle SK, et al. Mortality Benefits for Replacing Sitting Time with Different Physical Activities. Med Sci Sports Exerc. 2015;47:1833-40.

26. Paul L, Wyke S, Brewster S, Sattar N, Gill JMR, Alexander G, et al. Increasing physical activity in stroke survivors using STARFISH, an interactive mobile phone application: a pilot study. Top Stroke Rehabil. 2016;23:170-7.

27. English C, Healy GN, Olds T, Parfitt G, Borkoles E, Coates A, et al. Reducing Sitting Time After Stroke: A Phase II Safety and Feasibility Randomized Controlled Trial. Arch Phys Med Rehabil. 2016;97:273-80.

28. Michie S, Atkins L, West R. The Behaviour Change Wheel: A Guide to Designing Interventions. The Behavior Change Wheel: Book Launch Event. 2014;1-46 .

29. Michie S, Richardson M, Johnston M, Abraham C, Francis J, Hardeman W, et al. The behavior change technique taxonomy ( $v 1$ ) of 93 hierarchically clustered techniques: Building an international consensus for the reporting of behavior change interventions. Ann Behav Med. 2013;46:81-95. 
30. Kim J, Thrift AG, Nelson MR, Bladin CF, Cadilhac DA. Personalized medicine and stroke prevention: Where are we?. Vascular Health and Risk Management. 2015;11:601-11.

31. Sucharew H, Khoury J, Moomaw CJ, Alwell K, Kissela BM, Belagaje S, et al. Profiles of the national institutes of health stroke scale items as a predictor of patient outcome. Stroke. 2013;44:2182-7.

32. Delbecq AL, Van de Ven AH, Gustafson DH. Group Techniques for Program Planning: a guide to nominal group and Delphi processes. 1986. 174.

33. Chastin SFM, Winkler EAH, Eakin EG, Gardiner PA, Dunstan DW, Owen N, et al. Sensitivity to Change of Objectively-Derived Measures of Sedentary Behavior. Meas Phys Educ Exerc Sci. 2015;19:138-47.

34. Ezeugwu VE, Garga N, Manns PJ. Reducing sedentary behaviour after stroke: perspectives of ambulatory individuals with stroke. Disabil Rehabil. 2017;39:2551-2558.

35. Chastin S, Fitzpatrick N, Andrews M, DiCroce N. Determinants of Sedentary Behavior, Motivation, Barriers and Strategies to Reduce Sitting Time in Older Women: A Qualitative Investigation. Int J Environ Res Public Health. 2014;11:773-91.

36. Prince SA, Saunders TJ, Gresty K, Reid RD. A comparison of the effectiveness of physical activity and sedentary behaviour interventions in reducing sedentary time in adults: A systematic review and metaanalysis of controlled trials. Obes Rev. 2014;15:905-19.

37. Gardner B, Smith L, Lorencatto F, Hamer M, Biddle SJ. How to reduce sitting time? A review of behaviour change strategies used in sedentary behaviour reduction interventions among adults. Health Psychol Rev. 2016;10:89-112.

38. Martin A, Fitzsimons C, Jepson R, Saunders DH, van der Ploeg HP, Teixeira PJ, et al. Interventions with potential to reduce sedentary time in adults: systematic review and meta-analysis. Br J Sports Med. 2015;49:1056-63.

39. Saunders DH, Mead GE, Fitzsimons C, Kelly P, van Wijck F, Verschuren O, et al. Interventions for reducing sedentary behaviour in people with stroke. Cochrane Database Syst Rev. 2018;.

40. Nicholson S, Sniehotta FF, van Wijck F, Greig C a, Johnston M, McMurdo MET, et al. A systematic review of perceived barriers and motivators to physical activity after stroke. Int J Stroke. 2013;8:357-64.

41. Lentferink AJ, Oldenhuis HKE, De Groot M, Polstra L, Velthuijsen H, Van Gemert-Pijnen JEWC. Key components in ehealth interventions combining self-tracking and persuasive eCoaching to promote a healthier lifestyle: A scoping review. Journal of Medical Internet Research. 2017;19

42. van Gemert-Pijnen JEWC, Nijland N, van Limburg M, Ossebaard HC, Kelders SM, Eysenbach G, et al. A holistic framework to improve the uptake and impact of eHealth technologies. Journal of medical Internet research. 2011;13 
43. Boosman H, Van Heugten CM, Winkens I, Heijnen VA, Visser-Meily JMA. Awareness of memory functioning in patients with stroke who have a good functional outcome. Brain Inj. 2014;28:959-64.

44. Nijsse B, van Heugten CM, van Mierlo ML, Post MWM, de Kort PLM, Visser-Meily JMA. Psychological factors are associated with subjective cognitive complaints 2 months post-stroke. Neuropsychol Rehabil. 2017;27:99-115.

45. Langhorne P, Coupar F, Pollock A. Motor recovery after stroke: a systematic review. Lancet Neurol. 2009;8:741-54.

46. Langhorne P, Bernhardt J, Kwakkel G. Stroke rehabilitation. Lancet. 2011;377:1693-702.

47. Rosewilliam S, Sintler C, Pandyan AD, Skelton J, Roskell CA. Is the practice of goal-setting for patients in acute stroke care patient-centred and what factors influence this? A qualitative study. Clin Rehabil. 2015;30:508-19.

48. Parsons JGM, Plant SE, Slark J, Tyson SF. How active are patients in setting goals during rehabilitation after stroke? A qualitative study of clinician perceptions. Disabil Rehabil. 2018;40:309-16.

49. Rosewilliam S, Roskell CA, Pandyan AD. A systematic review and synthesis of the quantitative and qualitative evidence behind patient-centred goal setting in stroke rehabilitation. Clinical Rehabilitation. 2011;25:501-14.

50. Stephenson A, McDonough SM, Murphy MH, Nugent CD, Mair JL. Using computer, mobile and wearable technology enhanced interventions to reduce sedentary behaviour: a systematic review and meta-analysis. Int J Behav Nutr Phys Act. 2017;14:105.

51. Fjeldsoe B. Systematic review of maintenance of behavior change following physical activity and dietary interventions. Healh Psychol 2011;30:99-109.

52. van Mierlo ML, Schröder C, van Heugten CM, Post MWM, de Kort PLM, Visser-Meily JMA. The influence of psychological factors on Health-Related Quality of Life after stroke: A systematic review. Int J Stroke. 2014;9:341-8

53. Michie S, Ashford S, Sniehotta FF, Dombrowski SU, Bishop A, French DP. A refined taxonomy of behaviour change techniques to help people change their physical activity and healthy eating behaviours: the CALO-RE taxonomy. Psychol Health. 2011;26:1479-98.

\section{Tables}

Table I: Search terms related to the step of the Behaviour Change Wheel 


\begin{tabular}{|c|c|c|}
\hline $\begin{array}{l}\text { Questions per } \\
\text { stage }\end{array}$ & & Search terms \\
\hline \multirow{2}{*}{$\begin{array}{l}\text { Stages } 1 \\
\text { Understand the } \\
\text { behavior }\end{array}$} & What should be the target behavior? & Sedentary behavio* AND stroke OR risk \\
\hline & $\begin{array}{l}\text { What motivations, barriers and } \\
\text { opportunities are identified with } \\
\text { regards to reducing sedentary } \\
\text { behavior? }\end{array}$ & $\begin{array}{l}\text { 'Sedentary behavio*' AND 'Barrier*' OR } \\
\text { 'Motivation' }\end{array}$ \\
\hline $\begin{array}{l}\text { Stage } 2 \text { Identify } \\
\text { intervention } \\
\text { functions }\end{array}$ & $\begin{array}{l}\text { What is the evidence on the } \\
\text { effectiveness of the possible } \\
\text { intervention functions in stroke } \\
\text { survivors with regards to reducing } \\
\text { sedentary behaviour? }\end{array}$ & $\begin{array}{l}\text { ‘Behavioural interventions' OR 'lifestyle } \\
\text { intervention' OR 'Selfmanagement' OR } \\
\text { 'Education' AND 'Sedentary Behaviour' AND } \\
\text { 'Stroke'\# }\end{array}$ \\
\hline \multirow{2}{*}{$\begin{array}{l}\text { Stage } 3 \text { Identify } \\
\text { behaviour } \\
\text { changes } \\
\text { techniques and } \\
\text { modes of } \\
\text { delivery }\end{array}$} & $\begin{array}{l}\text { What is the evidence on the } \\
\text { effectiveness of the possible BCTs } \\
\text { in stroke survivors with regards to } \\
\text { reducing sedentary behaviour? }\end{array}$ & \multirow{2}{*}{$\begin{array}{l}\text { intervention' OR 'Selfmanagement' OR } \\
\text { 'Education' AND 'Sedentary Behaviour' } \\
\text { 'Stroke"\# AND 'Behavioural interventions' OR } \\
\text { 'lifestyle intervention' OR 'Selfmanagement' OR } \\
\text { 'Education' OR 'Secondary Prevention' OR 'Risk } \\
\text { Reduction Behaviour' OR 'Lifestyle modification' }\end{array}$} \\
\hline & $\begin{array}{l}\text { What is the evidence on the } \\
\text { effectiveness of the possible modes } \\
\text { of delivery in stroke survivors with } \\
\text { regards to reducing sedentary } \\
\text { behaviour? }\end{array}$ & \\
\hline
\end{tabular}

\# 'Stroke' OR 'Brain Infarction' OR 'Cerebro Vascular Accident' OR 'CVA' OR 'Cerebral apoplexy' OR 'Poststroke ${ }^{\star \prime}$

Table II: Capabilities, opportunities, motivation and behavioural diagnosis, the results of step 4 of the Behaviour Change Wheel. 


\begin{tabular}{|c|c|c|c|c|c|}
\hline COM-B & $\begin{array}{l}\text { COM-B } \\
\text { Components }\end{array}$ & TDF & $\begin{array}{l}\text { What needs to } \\
\text { happen for } \\
\text { people with } \\
\text { stroke to reduce } \\
\text { sedentary } \\
\text { behaviour? }\end{array}$ & Motivators/barriers & $\begin{array}{l}\text { Intervention } \\
\text { function }\end{array}$ \\
\hline \multirow[t]{4}{*}{ Capability } & $\begin{array}{l}\text { Physical } \\
\text { capability }\end{array}$ & Physical skills & $\begin{array}{l}\text { Being capable } \\
\text { to replace } \\
\text { sitting with LPA }\end{array}$ & $\begin{array}{l}\text { Overcome motor } \\
\text { impairments, } \\
\text { therapeutic } \\
\text { exercise, short } \\
\text { activities, moving } \\
\text { throughout the day }\end{array}$ & Training \\
\hline & $\begin{array}{l}\text { Psychological } \\
\text { capability }\end{array}$ & Knowledge & $\begin{array}{l}\text { Having } \\
\text { sufficient } \\
\text { knowledge on } \\
\text { the health } \\
\text { consequences } \\
\text { of sedentary } \\
\text { time and } \\
\text { sedentary } \\
\text { bouts; }\end{array}$ & $\begin{array}{l}\text { Awareness of } \\
\text { health risks of } \\
\text { sedentary } \\
\text { behaviour }\end{array}$ & Education \\
\hline & & & $\begin{array}{l}\text { Having } \\
\text { sufficient } \\
\text { knowledge of } \\
\text { own sedentary } \\
\text { behaviour; }\end{array}$ & & \\
\hline & & & $\begin{array}{l}\text { Having } \\
\text { sufficient } \\
\text { knowledge } \\
\text { about how to } \\
\text { je } 17 / 26\end{array}$ & & \\
\hline
\end{tabular}


reduce

sedentary time

and interrupt

sedentary

bouts.

\begin{tabular}{|c|c|c|c|}
\hline $\begin{array}{l}\text { Cognitive and } \\
\text { interpersonal skills }\end{array}$ & $\begin{array}{l}\text { Having the } \\
\text { skills to } \\
\text { decrease } \\
\text { sedentary time; } \\
\text { Having the } \\
\text { skills to develop } \\
\text { specific plans } \\
\text { to interrupt } \\
\text { sedentary bouts } \\
\text { and reduce } \\
\text { sedentary time }\end{array}$ & $\begin{array}{l}\text { Self-motivation } \\
\text { and determination, } \\
\text { action planning, } \\
\text { self-monitoring }\end{array}$ & Training \\
\hline $\begin{array}{l}\text { Memory, attention } \\
\text { and decision } \\
\text { processes }\end{array}$ & $\begin{array}{l}\text { Remember to } \\
\text { decrease } \\
\text { sedentary time } \\
\text { and interrupt } \\
\text { sedentary } \\
\text { bouts; }\end{array}$ & Cognitive problems & $\begin{array}{l}\text { Training, } \\
\text { environmental } \\
\text { restructuring }\end{array}$ \\
\hline $\begin{array}{l}\text { Behavioural } \\
\text { regulation }\end{array}$ & $\begin{array}{l}\text { Break sitting } \\
\text { habits; } \\
\text { Self-monitoring } \\
\text { to observer }\end{array}$ & $\begin{array}{l}\text { Relaxation, } \\
\text { comfort, sitting is a } \\
\text { habit, sitting is a } \\
\text { reward }\end{array}$ & $\begin{array}{l}\text { Education, } \\
\text { training }\end{array}$ \\
\hline
\end{tabular}


sedentary

behaviour

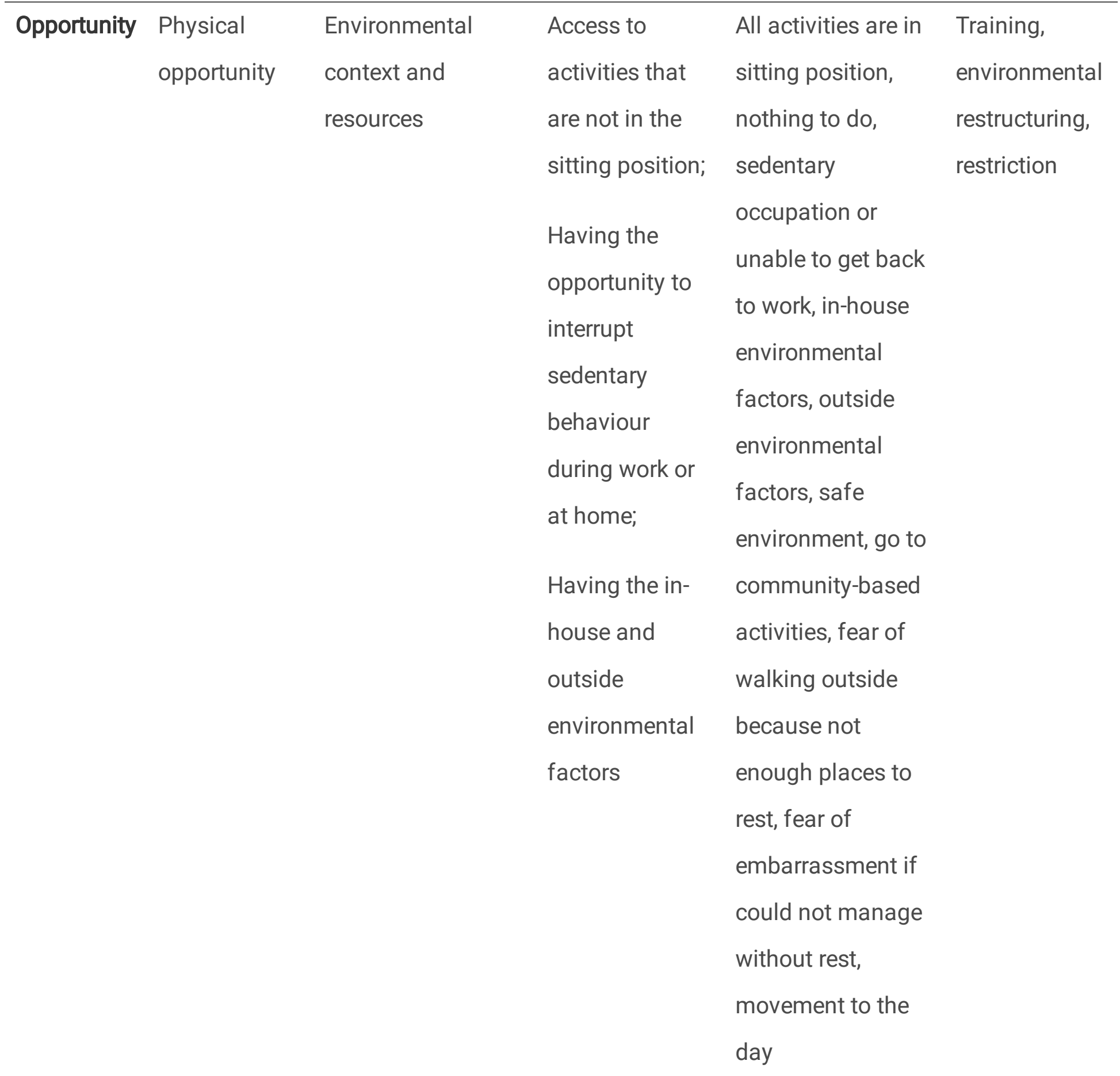

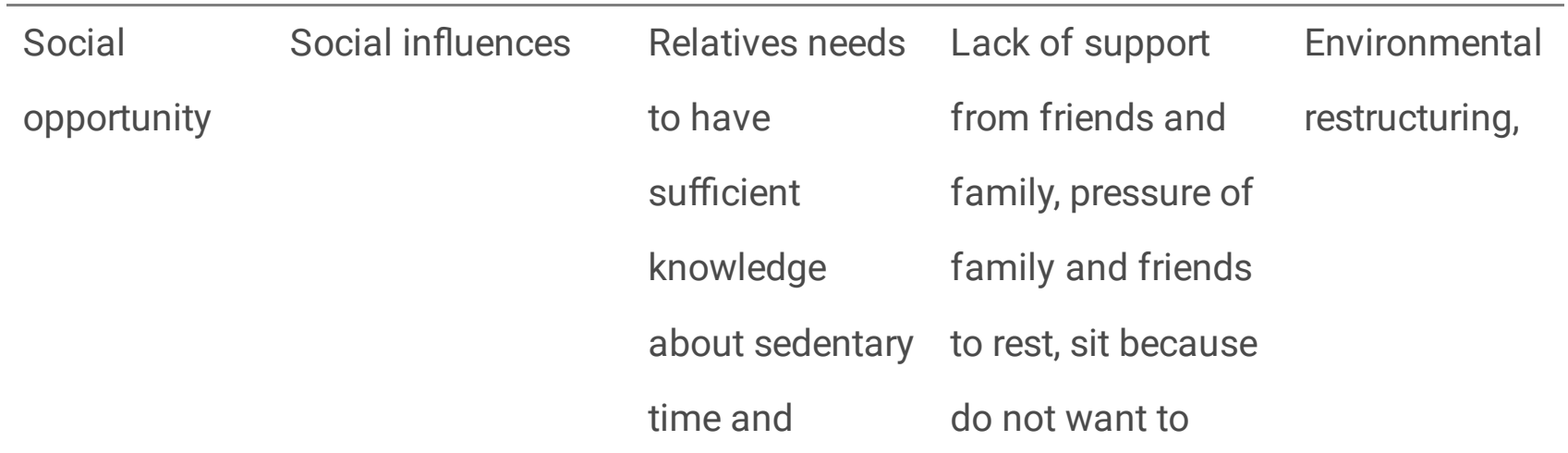




\begin{tabular}{|c|c|}
\hline interrupting & burden others, \\
\hline sedentary & feeling useful, \\
\hline bouts; & social support, \\
\hline Encourage, & socializing, relieve \\
\hline stimulate & boredom, not just \\
\hline decrease of & be the old person \\
\hline sedentary time & in the chair \\
\hline and interrupt & \\
\hline sedentary bouts & \\
\hline from friends & \\
\hline nd family; & \\
\hline
\end{tabular}

\begin{tabular}{|c|c|c|c|c|c|}
\hline Motivation & $\begin{array}{l}\text { Reflective } \\
\text { motivation }\end{array}$ & $\begin{array}{l}\text { Professional/social } \\
\text { role and identity }\end{array}$ & $\begin{array}{l}\text { Decrease } \\
\text { sedentary time } \\
\text { and interrupt } \\
\text { sedentary bouts } \\
\text { at the work } \\
\text { place }\end{array}$ & $\begin{array}{l}\text { Sedentary } \\
\text { occupation }\end{array}$ & $\begin{array}{l}\text { Education, } \\
\text { (persuasion) }\end{array}$ \\
\hline & & $\begin{array}{l}\text { Beliefs about } \\
\text { capabilities }\end{array}$ & $\begin{array}{l}\text { Overcome } \\
\text { fatigue, } \\
\text { depression, } \\
\text { cognitive } \\
\text { problems, pain, } \\
\text { poor sleep, } \\
\text { (self)- } \\
\text { monitoring of } \\
\text { behaviour to } \\
\text { have insight } \\
\text { about the } \\
\text { sedentary time }\end{array}$ & $\begin{array}{l}\text { Fatigue, } \\
\text { depression, } \\
\text { cognitive } \\
\text { problems, pain, } \\
\text { poor sleep, lack of } \\
\text { motivation, feel } \\
\text { capable of self- } \\
\text { caring, self- } \\
\text { motivation and } \\
\text { determination }\end{array}$ & $\begin{array}{l}\text { Education, } \\
\text { persuasion, } \\
\text { training }\end{array}$ \\
\hline
\end{tabular}


and sedentary

bouts;

Have self-

motivation and

determination;

\begin{tabular}{|c|c|c|c|}
\hline Optimism & $\begin{array}{l}\text { Cope with fear } \\
\text { of walking } \\
\text { outsides, fear of } \\
\text { embarrassment, } \\
\text { fear of falling } \\
\text { Motivated to } \\
\text { change } \\
\text { sedentary } \\
\text { behaviour; }\end{array}$ & $\begin{array}{l}\text { Fear of walking } \\
\text { outside, fear of } \\
\text { embarrassment, } \\
\text { fear of falling, feel } \\
\text { capable of self- } \\
\text { caring, feeling less } \\
\text { guilty, feeling } \\
\text { independent }\end{array}$ & $\begin{array}{l}\text { Education, } \\
\text { persuasion }\end{array}$ \\
\hline $\begin{array}{l}\text { Beliefs about } \\
\text { consequences }\end{array}$ & $\begin{array}{l}\text { Belief in the } \\
\text { positive effect } \\
\text { on the risk of } \\
\text { recurrent stroke, } \\
\text { pain, } \\
\text { depression, } \\
\text { feeling less } \\
\text { guilty, feeling } \\
\text { independent, } \\
\text { relieve }\end{array}$ & $\begin{array}{l}\text { Pain, depression, } \\
\text { feeling less guilty, } \\
\text { feeling } \\
\text { independent, } \\
\text { relieve boredom, } \\
\text { poor sleep, coping } \\
\text { mechanics to } \\
\text { relieve depression }\end{array}$ & $\begin{array}{l}\text { Education, } \\
\text { persuasion }\end{array}$ \\
\hline
\end{tabular}


boredom, poor

sleep

\begin{tabular}{|c|c|c|c|c|}
\hline & Intentions & $\begin{array}{l}\text { Have personal } \\
\text { motivation to } \\
\text { reduce } \\
\text { sedentary time } \\
\text { and interrupt } \\
\text { sedentary bouts }\end{array}$ & $\begin{array}{l}\text { Personal } \\
\text { motivation }\end{array}$ & $\begin{array}{l}\text { Education, } \\
\text { persuasion, } \\
\text { incentivisation }\end{array}$ \\
\hline & Goals & $\begin{array}{l}\text { Action planning; } \\
\text { Being active } \\
\text { during the day; }\end{array}$ & $\begin{array}{l}\text { Action planning, } \\
\text { being active during } \\
\text { the day, }\end{array}$ & $\begin{array}{l}\text { Education, } \\
\text { persuasion, } \\
\text { incentivisation }\end{array}$ \\
\hline $\begin{array}{l}\text { Automatic } \\
\text { motivation }\end{array}$ & Reinforcement & $\begin{array}{l}\text { Establish } \\
\text { routines to } \\
\text { interrupt } \\
\text { sedentary } \\
\text { bouts; } \\
\text { Create other } \\
\text { habits instead } \\
\text { of sitting; }\end{array}$ & $\begin{array}{l}\text { Sitting is a habit, } \\
\text { nothing to do }\end{array}$ & $\begin{array}{l}\text { Training, } \\
\text { environmental } \\
\text { restructuring }\end{array}$ \\
\hline
\end{tabular}

\begin{tabular}{lll}
\hline Emotion & Experience a & Fatigue, Incentivisation \\
positive & depression, fear of \\
emotional & walking, fear of \\
response & embarrassment, \\
decreasing & fear of falling, \\
sedentary time & feeling \\
and interrupt & independent, \\
sedentary bouts & feeling useful, \\
& feeling less guilty
\end{tabular}


Com-B=Capabilities, opportunities, motivation and behavioural diagnosis, TDF=Theoretical Domains Framework, LPA=Light Physical Activity

Table III: Final ranking BCTs per profile 


\begin{tabular}{|c|c|c|c|c|}
\hline & $\begin{array}{l}\text { Patients without } \\
\text { physical nor } \\
\text { cognitive } \\
\text { impairments }\end{array}$ & $\begin{array}{l}\text { Patients with cognitive } \\
\text { impairments and without } \\
\text { physical impairments }\end{array}$ & $\begin{array}{l}\text { Patients with physical } \\
\text { impairments and without } \\
\text { cognitive impairments }\end{array}$ & $\begin{array}{l}\text { Patient with both } \\
\text { physical and } \\
\text { cognitive } \\
\text { impairments }\end{array}$ \\
\hline 1. & $\begin{array}{l}\text { Goal setting } \\
\text { (behaviour) }\end{array}$ & Goal setting (behaviour) & Goal setting (behaviour) & $\begin{array}{l}\text { Goal setting } \\
\text { (behaviour) }\end{array}$ \\
\hline 2 . & Action planning & Action planning & Problem solving & $\begin{array}{l}\text { Social support } \\
\text { (unspecified) }\end{array}$ \\
\hline 3. & $\begin{array}{l}\text { Social support } \\
\text { (unspecified) }\end{array}$ & $\begin{array}{l}\text { Social support } \\
\text { (unspecified) }\end{array}$ & Action planning & Prompts/cues \\
\hline 4. & $\begin{array}{l}\text { Self-monitoring } \\
\text { (behaviour) }\end{array}$ & Prompts/cues & $\begin{array}{l}\text { Social support } \\
\text { (unspecified) }\end{array}$ & Problem solving \\
\hline 5. & $\begin{array}{l}\text { Goal setting } \\
\text { (outcome) }\end{array}$ & $\begin{array}{l}\text { Restructuring the physical } \\
\text { environment }\end{array}$ & $\begin{array}{l}\text { Self-monitoring } \\
\text { (behaviour) }\end{array}$ & $\begin{array}{l}\text { Restructuring the } \\
\text { social environment }\end{array}$ \\
\hline 6. & $\begin{array}{l}\text { Feedback on } \\
\text { behaviour }\end{array}$ & Problem solving & $\begin{array}{l}\text { Restructuring the physical } \\
\text { environment }\end{array}$ & $\begin{array}{l}\text { Restructuring the } \\
\text { physical } \\
\text { environment }\end{array}$ \\
\hline 7. & $\begin{array}{l}\text { Discrepancy } \\
\text { between current } \\
\text { behaviour and goal }\end{array}$ & Social support (practical) & $\begin{array}{l}\text { Restructuring the social } \\
\text { environment }\end{array}$ & Action planning \\
\hline 8. & $\begin{array}{l}\text { Information about } \\
\text { health } \\
\text { consequences }\end{array}$ & $\begin{array}{l}\text { Restructuring the social } \\
\text { environment }\end{array}$ & Goal setting (outcome) & $\begin{array}{l}\text { Social support } \\
\text { (practical) }\end{array}$ \\
\hline 9. & Problem solving & Graded tasks & Feedback on behaviour & Graded tasks \\
\hline 10. & $\begin{array}{l}\text { Restructuring the } \\
\text { social environment }\end{array}$ & $\begin{array}{l}\text { Social reward \& feedback } \\
\text { on behaviour }\end{array}$ & $\begin{array}{l}\text { Information about health } \\
\text { consequences }\end{array}$ & $\begin{array}{l}\text { Social reward \& } \\
\text { review behaviour } \\
\text { goal(s) }\end{array}$ \\
\hline
\end{tabular}




\section{Figures}

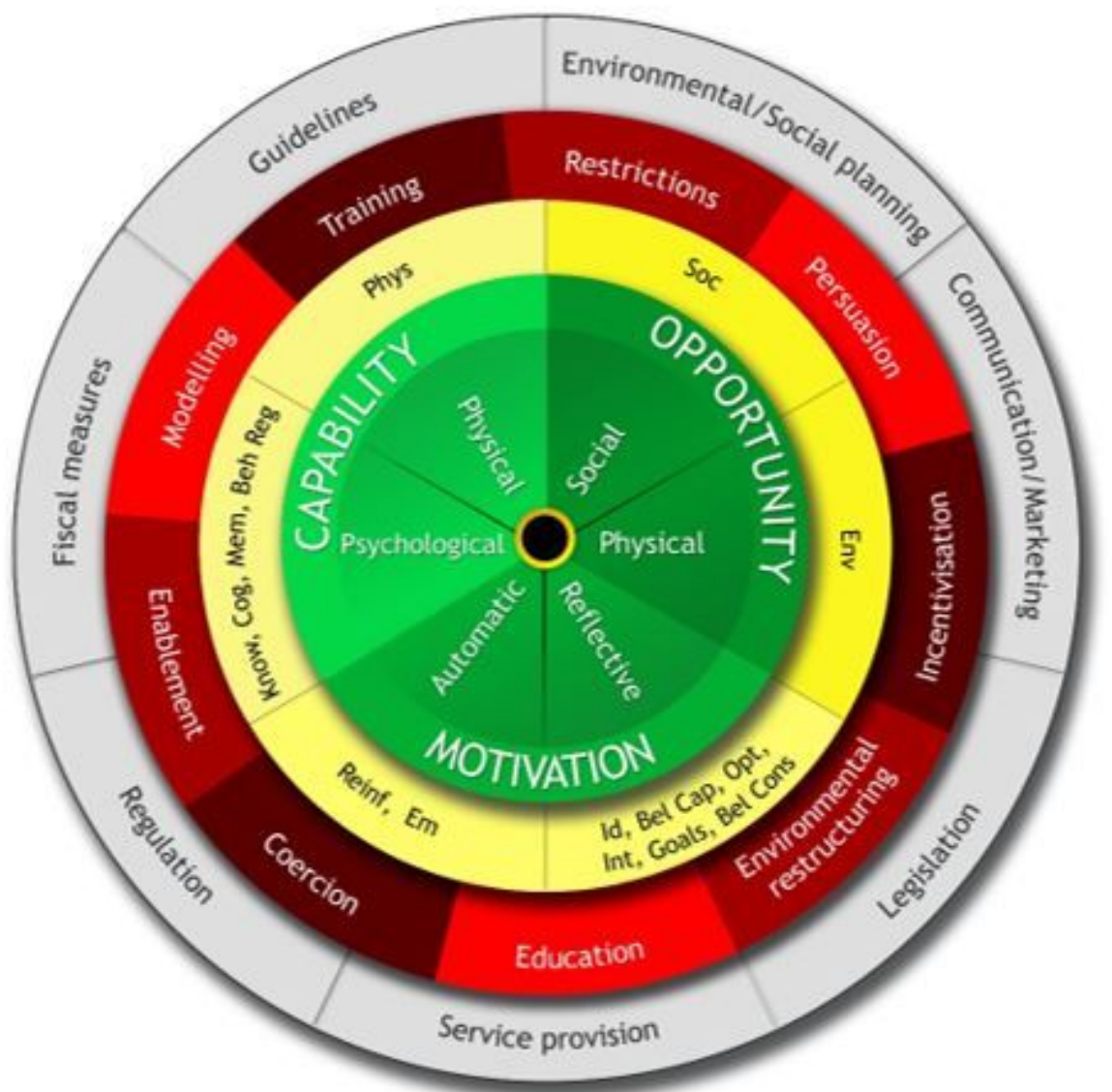

\section{Figure 1}

The behaviour change wheel and Theoretical Domains Framework. Reprinted with permission from Michie et al (Michie et al., 2011). 
Stage 1:

Understand the

behavior

1. Literature search to define, select and specify target behavior

2. Literature search to identify motivators, barriers and opportunities

3. Connecting motivators, barriers and opportunities to the COM-B model and TDF

\section{Stage 2: Identify \\ intervention \\ functions}

1. Literature search to identify effective intervention functions

2. Connecting effective intervention functions to the COM-B model and TDF
Stage 3: Identify

BCTs and modes

of delivery

1. Literature search to identify effective BCTs and modes of delivery

2. Nominal group techniques to select $\mathrm{BCT}$ s to reduce sedentary behavior in people with stroke

\section{Figure 2}

Stages and used methods per stage.

\section{Supplementary Files}

This is a list of supplementary files associated with this preprint. Click to download.

- Supplemantarymaterials.docx 